\title{
FORMATION OF PROFESSIONAL COMPETENCIES FOR SOCIAL WORK FOR THE STUDENTS OF SOCIAL PEDAGOGY
}

\author{
Ts. Delcheva* \\ Department of Pedagogical and Social Sciences, Faculty of Education, Trakia University, Stara \\ Zagora, Bulgaria
}

\begin{abstract}
The issues with professional competencies and the process of forming such competencies are gaining more and more significance under the conditions of contemporary workforce education and further professional realization. The purposeful mastering of a set of specific skills, knowledge and conduct is a precondition for adequate professional realization and development. The acquisition of quality knowledge and the processing of such knowledge through personal experience and different manifestations of social and economical reality is a major trend in the educational processes for contemporary higher education. Active and interactive education methods rank among the most prospective methods for professional training of specialists. The paper treats the possibilities for forming professional competencies in the process of training social pedagogy students through the applications of the following approaches to the planning and conduct of tuition: the competency-based, the systematic, and the constructivist approaches. Special emphasis is placed upon the classes for exercise and the workshops in Social Pedagogy and Social Work. Particular attention is given to the significance of the organizing and conducting of the training practice for the acquisition of professional competencies for social work and for the support of the realization of young people with higher education on the labor market.
\end{abstract}

Key words: professional competencies, social work, training practice

\section{INTRODUCTION}

Under the conditions of contemporary social development, the issue of professional competencies is gaining greater theoretical and practical significance.

This is also the direction and the scope of the study, part of which is presented in the current paper.

The term 'competency' is normally used in many fields, and is difficult to define. For the purpose of our work we usually assume that 'competency' denotes 'the ability to perform actions', 'power or potential to act', in the specific situation of the worker. (1)

In the Faculty of Pedagogics of the Trakia University of Stara Zagora, Social pedagogy students receive training which allows them to achieve professional realization in several directions. One possible realization after graduating with a bachelor's degree is joining

${ }^{*}$ Correspondence to: Tsveta Apostolova Delcheva, tsveta.delcheva@trakia-uni.bg, +359886 367893 the structures of the Agency for Social Assistance (ASA), municipal social structures and the adjoining social institutions.

Recruiting personnel for newly created social structures through a competitive examination has become a practice. If the position does not involve managerial functions, competitive examinations are divided in two parts document selection and interview. Applicants with no work experience pass the first stage only formally. The interview is more important for the selection of the team. At the interview, applicants can compensate for their short professional resume through the demonstration of knowledge and skills, acquired in the course of university education. The criteria for assessment of the applicants are based on the Ordinance for the Terms and Order for Assessment of the Performance of Employees of the State Administration (2), and are listed in a Form for Applicant Assessment at Interviews for Expert Positions (3) as follows: Analytical competency; Result-orientation; Team work; Communication competency; Client-focus (internal/external); Professional competency. 
The study is aimed at the forming of professional competencies in social pedagogy students in the course of education in Basics and methods of social work and the training practice, through the development of a didactic system. The didactic system consists of the goals and contents of the course, in coordination with the requirements of the actual practice.

The presented results for the school year 2014/2015 show the approbation of elements from the system of cognitive elements in the education of second- and third-year students, based on the following indicators: 1. Degree of mastering of devices, methods and techniques for social work. 2. Degree of formation of specific skills conduct and analysis of a social survey, working on a case.

\section{KNOWLEDGE OF THE LEGISLATION IN THE SOCIAL SPHERE AND ITS CORRECT APPLICATION AS AN INDICATOR FOR PROFESSIONAL COMPETENCE}

The multitude of options for professional realization of social pedagogues requires knowledge and skillful work with many normative documents, relatively different in terms of content. One of the requirements of employers is for the graduate social pedagogues to know and properly apply the legislation in the social sphere. Meanwhile, knowledge and proper application of the legislation in the working sphere are also normative indicators for assessment of professional competency. Knowing the normative documents for the sake of knowing is resented by students. In their opinion, the use and reliance to normative sources in the actual social work is inapplicable. Those are a priority of bureaucrats, who - through putting an accent on the lawfulness of the communication with clients - disguise their professional unfitness. Such negative attitude provokes a new form of reinvention and reconsideration of the relation between the theoretical knowledge and the skills, required for their adequate realization in practice.

Using cases as a method is a preferable form of exercise on the acquired theoretical knowledge. In the process of solving a particular problem from the practice, students follow steps that are extremely close to the basic stages of social work as a whole. They start with a description of the situation, which relates to orientation on the problem and identification of the needs of the client. After that the student/social worker carries out assessment of that situation from the position of his/her particular professional role, i. e. he/she analyzes and assesses the case. The next stage in social work, which also implies to the solution of the case, is to determine the goals and tasks and to draft an initial action plan for working with the client. Based on professional experience, the student/social worker lays out different solutions to the client's problem. The methods for work and intervention are selected at this stage. At the end, a forecast assessment is performed and then the client is presented with the right to make his/her choice. Through solving different cases, the students also form skills for using the method as a means for interacting with clients.(4) In spite of the positive characteristics, listed above, the application of the cases as a method for verification of theoretical knowledge alone is not efficient enough. On one hand, solving cases from the practice continues being a desired form of exercising theoretical knowledge in different subjects (including Basics and methods for social work - BMSW) for the students. On the other hand, while the exercises are good as 'gymnastics for the brain' and for demonstration of knowledge on different subjects as well as of social experience, they lack the element of practical applicability. The possible choices, presented to the client do not match the social reality. In the lections course of the subjects, students do get the opportunity to build a wholesome image of the current situation in our country. However, their solutions bristle with conventions and lack the resource to turn into a model for solving a particular social problem, suitable for direct application into practice.

This forces aiding the process with additional techniques. The skill of seeing the acquired theoretical knowledge through the viewpoint of legislation is formed in the BMSW exercise classes through the development of individual tasks and the use of auxiliary work cards for case solving.

At the time when the first individual task was assigned to the students, it was emphasized that the solutions they present will be used by all of them through the whole course of education in BMSW and through the training practice, in some of the training locations. Depending on the particular professional realization in the future, that knowledge will aid the process of adaptation at the job. The students were presented with the following options: a list of notions, related to social work, the definitions of which had to be found in normative sources and in scientific research, 
with correct reference to the sources. In subsequent exercises, the presented texts are referenced continuously, and the differences and similarities between them are analyzed.

The work cards, used in the exercises are excerpts from legislative and non-legislative acts. The students are instigated to apply those in the solutions of the cases, thus providing solutions which are much closer to the current reality. In this way, students learn to approach with greater precision to the selection of methods for working with clients with different social problems.

\section{KNOWLEDGE OF THE STRUCTURE} AND FUNCTIONS OF THE INSTITUTIONAL WORK ENVIRONMENT AND THE PRINCIPLES AND RULES OF ITS ACTIVITIES AS AN INDICATOR FOR PROFESSIONAL COMPETENCY AND AN EFFECTIVE ANSWER TO THE NEEDS, INTERESTS AND EXPECTATIONS OF THE CLIENTS BMSW case solving has presented another problem, which is also the second indicator for professional competency: the need of knowing the structure and the functions of the institution in which the social worker/social pedagogue operates, as well as its position in the network of institutions that relate to solving the social problems of a client or a whole target group.

Students understand that their own understanding and orientation in the network of institutions is related to their ability to direct their activities to the client in order to meet the client's needs, interests and expectations effectively. During the exercise classes the students can build up their knowledge on the subject of Social Pedagogy while they get acquainted to the specificity of the elements of the social services system. Auxiliary devices for case solving include short informational videos for the activities and clients of different social services for children and adults. Work cards that visualize the structure of state and municipal institutions as well as the network of institutions and non-government organizations that work in the social sphere are also used in solving different social problems of clients or groups of clients.

Simultaneously, an emphasize was placed on the different professional roles which can be performed by the social pedagogue, and respectively, the role/position from which he/she should approach the client, or other specialists within or outside a given institution in the process of communication.
Students are presented work cards, which contain excerpts from job descriptions. Those work cards are an additional reference point for decision-making, as well as for training skills for competent assistance to the client, according to the powers of the professional position and those of the institution.

Working people are expected to maintain positive attitude towards all clients, to honor their rights and respect their interests in the whole process of execution of duties.

Exercising skills for interviewing clients is the first step in that direction. Assuming the role of professionals, students exercise to apply what they have learned in Basics and methods of social work and other subjects as well. They focus on the specifics of the interview in social work with an emphasis on the skills for acquiring an informed consent from the client. In the process for acquiring the informed consent, it is very important that the professional social worker presents the client with the advantages and risks of the offered service, impartially and in full. (4) Provocations from 'clients'/ students, that play the role of clients/ can be grouped in three basic directions: getting immediate guarantee for persistence; concretization of support; discarding the anonymity of the professionals, involved in support. On the feedback form for the role of the social worker, three-quarters of the students give a high assessment of their own participation in situations with 'difficult' clients and clients with different disabilities, in terms of overcoming the specific behavior of clients from those groups. Meanwhile, more than half of the students state that they felt insecurity in the process of communicating with the 'clients', which prevented them from keeping their positive attitudes until the end of the interview. As a reason for their insecurity they point out: not knowing the structure of the institutions and the support options they provide, lack of information about the essence and location of the offered social services, i. e. they state their need to reconsider the mechanisms of social support in practice.

Working on a case is a leading part of individual social work. Professionals face different requirements in making it efficient. This problem is presented in the theoretical works (4-6), as well as in the internal documentation of the Agency for Social Assistance. The directorates of Social Welfare use the Methodics for case management for protection of children in risk by the Child Protection department. Case work is divided into 4 major phases. 
During the first phase the specialist orientates in the situation in the presence of the client, using the information, provided by the client. Many clients are incapable of formulating their major problems. The identification of those problems results from the worker's skills to communicate with the client and to collect the most reliable information from the client. Thus, some of the exercises in the subject of BMSW are aimed at training skills for conducting a social survey and preparing a social report - the social survey is the main method for collecting information, while the social report is the form in which information is arranged in order to draft the directions for social work on the particular case.

Based on a standardized social report for undertaking measures for protection of a child in social risk, (7) the students prepare questions through which they acquire reliable information from clients of different ages and in different situations of social risk. The task is carried out in small groups. The small group is unified by the delivery of the end product, as well as by the self-assessment on a 3-level scale: 'We succeeded with the task', 'We succeeded partially', 'We failed with the task', and explain their choice. In 5 out of 6 groups the self-assessment is 'We succeeded with the task', one group have accessed their performance as 'partially successful'. After the products were presented to the larger group, the students were asked to self-assess their performance again. Two groups changed their self-assessment from 'We succeeded with the task' to 'We succeeded partially'. Students from those two groups explained the change of opinion as a result from the fact that in the process of presentation to the larger group, they identified that they lack enough experience and skill to consider problems from the viewpoints of different clients.

\section{DEVELOPMENT OF PROFESSIONAL COMPETENCIES IN THE PRACTICE}

In the curriculum for the subject Social pedagogy, during the sixth and seventh semester, one day per week is scheduled for training practice in different pedagogical and social institution. This class is of particular value to the students.

Through such activities students get the chance to apply into practice the knowledge and skills, acquired through academic studies and to develop their professional and analytical competencies towards orientation in the structure of a particular social problem and the reasons for it. They train their skills to critically analyze different viewpoints and to convincingly back with arguments their position on the solving of the particular case. They meet clients - of different age, with different problems and social experience. They get the opportunity to interact with the clients of a particular institution from the position of a social worker, social pedagogue and social advisor, yet under the supervision of their training mentor.

During the training practice each student keeps a diary. In the current paper we present several conclusions, drawn from the detailed analysis of 36 student diaries from two years as well as from the problems, identified in the conference classes for training practice. At the end of the training practice the students:

- $\quad$ Recognize in due time and properly name different social institutions;

- $\quad$ Orientate in the legislation and manage to determine which are the legislative acts that apply to a particular target group/customer;

- Carry out assessment of the needs of the client, analyzing his/her strong and weak points;

- Are capable of identifying several possible solutions to a problem.

At the end of the term, moments from the exercises from the training practice classes find another application in the students' portfolios. The final product of the whole practical process of education is the case study model the description of a case in the pre-graduation practice of the students.

\section{CONCLUSION}

The study shows that the competencies, listed as criteria in the legislation are supplemental, mutually dependent and mergeable, which is yet another challenge to the planning and realization of the educational process, aimed at forming such competencies.

Our society still holds the concept that the profession of the social worker 'is rather a vocation than a professional manifestation of specific competencies'. (8) On the other hand, the social worker is expected to have knowledge and skills for professional service in the social sphere. To meet such expectations and requirements, the training of the students in Basics and methods of social work during the classes for training practice should be directed towards the acquisition of competencies for social work through enrichment of personal experience and pragmatically oriented strategies and techniques. 


\section{REFERENCES}

1. Development of standards for social work in specific EU-member states, an MLSP report, 2006.

https://www.google.bg/url?sa=t\&rct=j\&q= \&esrc $=$ s\&source $=$ web \&cd $=1 \&$ cad $=$ rja \&uac $\mathrm{t}=8 \&$ ved $=0 \mathrm{CB} 8 \mathrm{QFj} \mathrm{AA} \& \mathrm{url}=\mathrm{http} \% 3 \mathrm{~A} \% 2 \mathrm{~F}$ $\% 2$ Fbulgaria.naric.org.uk\%2Fdocuments $\%$ 2FStage_1_ReportBG.doc\&ei=qFeSVaaM HMOqsAGJ_pfYCw\&usg=AFQjCNHTzY 40BrynVC_Q0xzNa5WY44zrIA\&bvm=bv. 96783405,d.bGg

2. Ordinance for the Terms and Order for Assessment of the Performance of Employees of the State Administration /adopted by Government Decree \#129 from 26.06.2012/.

http://www.lex.bg/bg/laws/ldoc/2135799917

3. Decree 129 from June 26th 2012 for the reception of a classification of administrative appointments, an ordinance for the application of the classification of administrative appointments, an ordinance for the remuneration of employees in the state administration, an ordinance for the rules and conditions for assessment of the performance of employees in the state administration, and an ordinance for the job descriptions of state employees - enacted on July 1st 2012, published in State Gazette issue 49 from June 29th 2012.

http://www.lex.bg/bg/laws/ldoc/2135799919

4. Rangelova, E. \& Mehandzhiyska, G., Methods of social work, Gabrovo, 2009.

5. Todorova, M., A handbook on methods for social work, Veliko Tarnovo, 2005.

6. Petrova Dimitrova, N. Fundamentals and methods of social work, Sofia, 2013.

7. Structure of a social report for undertaking measures for protection of a child - Agency for Social Assistance

http://www.asp.government.bg/ASP_Files/i nternal_site/UP-ZZD/\%D1\%85\%D1\%859100_0125_\%D0\%BE\%D1\%82_04-052010__14_38_1.doc

8. Delcheva, Tsveta, Formation of basic knowledge, skills and competences, applicable in social work in the students of social pedagogy through social pedagogy trainings. // Education in Balkans Today. The 5th international Balkan education and science congress. CD, Edirne, 2009. 